\title{
EXPERIMENTOS SIMPLES PARA ESTUDO DE GRANÉIS
}

\author{
F. O. MILHOMEM* e J. A. M. DA LUZ \\ Universidade Federal de Ouro Preto - Programa de Pós Graduação em Engenharia Mineral. \\ felipe.milhomem6@gmail.com*
}

Artigo submetido em maio/2014 e aceito em abril/2016

DOI: $10.15628 /$ holos.2016.2126

\section{RESUMO}

Embora haja exigência cada vez maior de um ensino integrado entre teoria e prática, com contextualização dos tópicos abordados, o que ainda se verifica em várias instituições de ensino é a clássica forma de aprendizagem focada na memorização do conteúdo, notadamente nas ciências naturais, de fórmulas, sem, contudo, entender os conceitos por detrás das equações ou mesmo sua utilização prática. Sistemas particulados densificados, conhecidos como granéis, são muito comuns em diversas áreas, como a alimentícia, a farmacêutica, a mineração, a construção civil dentre outros. Neste artigo, experiências simples são propostas para se estudar granéis como atividades extracurriculares junto a alunos do segundo grau. As características estudadas foram: análise de distribuição de tamanhos, massa específica real e aparente, porosidade, esfericidade, índice de Hausner, ângulo de repouso dinâmico e vazão de escoamento. As metodologias propostas se mostraram reprodutíveis e facilmente mensuráveis. Tais atividades podem ser executadas de forma a levar os alunos à contextualização de diversos conceitos matemáticos e físicos no mundo real.

PALAVRAS-CHAVE: granéis, sistema particulado, experimento, escoamento

\section{SIMPLE EXPERIMENTS FOR PARTICULATE SYSTEMS ANALYSIS}

\begin{abstract}
While there is growing demand for an integrated education between theory and practice and with contextualization of studied issues, the classic form of focused learning on memorization remains in many educational institutions. Especially in the natural sciences, formulas are memorized without the understanding of the concepts behind the equations or even their everyday application. Densified particulate
\end{abstract}

systems are very common in various sectors such as food industry, pharmaceutics, mining, construction and others ones. In this article, simple experiments are proposed for bulk solids study that can help as extracurricular activities directed to high school students, in order to contextualize some mathematical and physical phenomena in the real world.

KEYWORDS: granular materials, particulate system, experiment, flow. 


\section{INTRODUÇÃO}

Dentre os sistemas particulados, os constituídos de partículas sólidas em contato com suas vizinhas circunjacentes, de modo inconsolidado (não coesos), frequentemente com diferentes tamanhos e formas são usualmente descritos granéis, ou sistemas particulados densificados (para se distinguirem dos ditos rarefeitos, como as poeiras, e gases).

Granéis encontram-se presentes nas mais variadas áreas, como indústria alimentícia, farmacêutica, construção civil, mineração, hidrologia, engenharia química, agricultura, tratamento de esgoto, dentre outros. Apesar de sua ubiquidade, ainda não se obteve a completa descrição quantitativa dos fenômenos associados aos granéis, uma vez que são sistemas complexos, e o conhecimento adquirido sobre fluidos geralmente não pode ser aplicado irrestritamente a eles.

Dada tal complexidade, o conhecimento de suas propriedades físicas deve ser feito considerando o conjunto, devido tanto à heterogeneidade dos elementos constituintes do sistema, como devido às propriedades individuais de cada partícula, que se modificam, quando se considera o sistema como um todo.

Assim, sistemas particulados apresentam comportamento complexo, podendo, ademais, ser considerados como sistemas metaestáveis. Tais sistemas não se comportam nem como líquidos, gases ou sólidos, conforme discutido por Lopes et alii (2008).

Neste trabalho, sugerem-se experimentos, utilizando como materiais areia e microesferas de vidro, que permitem analisar algumas importantes propriedades de sistemas particulados densificados.

Tais experimentos, concebidos para ilustrar a caracterização de granéis, foram realizados com aparato relativamente simples e de aceitável reprodutibilidade.

\section{ALGUMAS CARACTERÍSTICAS DOS GRANÉIS}

Como mencionado anteriormente, os granéis são encontrados em diversos setores industriais, e certas características são mais importantes em uns ramos, em detrimento de outras.

Neste estudo, as principais características levadas em conta foram: 1) análise de distribuição de tamanhos, 2) massa específica real e aparente, 3) porosidade, 4) esfericidade, 5) índice de Hausner, 6) ângulo de repouso e 7) velocidade de escoamento. A importância de cada uma delas será abordada a seguir.

Em inúmeras instâncias, é importante determinar a distribuição de tamanho em que as partículas se apresentam. Isso porque as várias operações as quais as mesmas são submetidas apresentam maior ou menor eficiência dependente do tamanho (máximo ou mínimo) apresentado ao processo ou da proporção (distribuição) dos mesmos na população submetida ao dito processo. Além disso, inúmeros produtos exigem especificações de tamanho, como é o caso, por exemplo, da indústria de minérios, de agregados para a construção, ou de fabrico do cimento Portland. Usualmente, associadas à cominuição, há operações de fracionamento granulométrico, como o peneiramento e a classificação em meios fluidos (comumente ar ou água). É comum discretizar a distribuição estatística de tamanho empregando-se série de crivos ou peneiras. 
Na Figura 1 é exemplificado o processo de peneiramento para análise granulométrica.

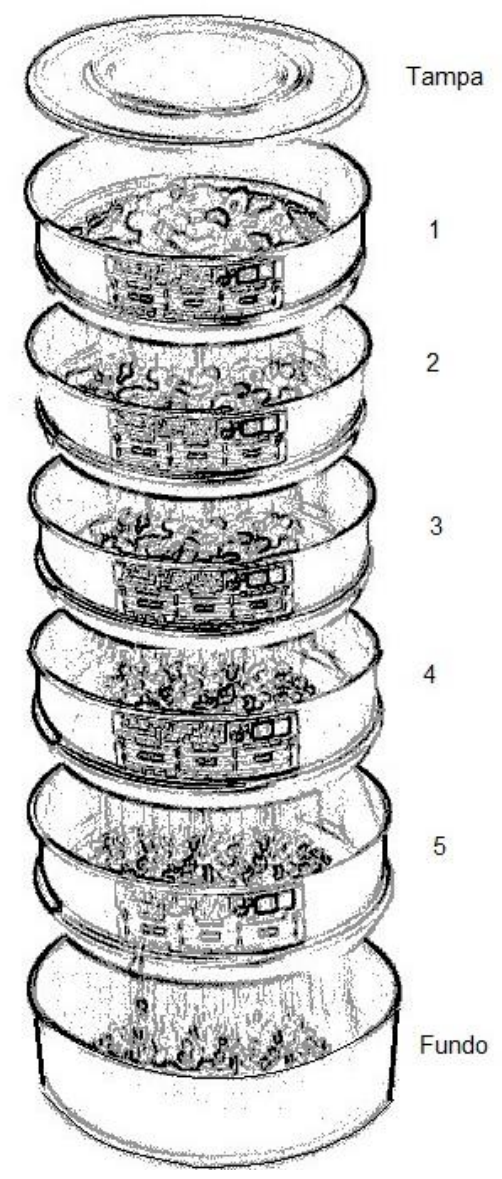

Figura 1: Vista explodida de série com cinco peneiras para análise granulométrica (modificado de BERTEL, 2015).

O resultado do peneiramento pode ser apresentado na forma de uma curva de frequência (simples ou acumulada). Em razão de as fraturas na fragmentação serem dependentes de inúmeras causas, a distribuição de frequência de tamanhos, em primeira análise, poderia ser cogitada como equação normal da estatística (a equação em forma de sino, devida a De Moivre, Laplace, Galton e Gauss), já que ela ocorre quando a gênese de um sistema é produto da interveniência de inúmeras variáveis aleatórias independentes (a rigor infinitas), sem que haja preponderância de nenhuma delas (na verdade, materialização do chamado teorema do limite central da estatística).

Contudo, muito raramente a distribuição granulométrica possui aderência estatística com a distribuição normal, indicando que há a prevalência de fenômenos complexos, como a clivagem, a fragmentação preferencial de partículas maiores, etc. Isso leva a uma assimetria na curva, resultando mais massa de partículas menores do que maiores, quando tais proporções são comparadas com as esperadas pela distribuição de Gauss (sino, ou ogiva simétrica).

Assim, é comum que, se o logaritmo do tamanho for tomado em vez do valor do tamanho propriamente dito, o sistema seja matematicamente descrito com maior adequação por uma curva "normal" (é a chamada distribuição log-normal). Essa equação, contudo, é de difícil manipulação algébrica (e não Riemann-integrável, exigindo o uso de tabelas estatísticas).

Uma equação de distribuição muito utilizada, por comumente dar boa aderência estatística aos pontos experimentais é a de Rosin-Rammler, mostrada a seguir. 
$Y=1-\exp \left[\ln \left(\frac{1}{2}\right) \times\left(\frac{\frac{x}{x_{\max }-x}}{\frac{x_{50}}{x_{\max }-x_{50}}}\right)^{n}\right]$

Onde:

$\boldsymbol{Y}$ - fração de material passante acumulado (menor que a abertura $\boldsymbol{x}$ ) [-];

$\boldsymbol{x}$ - tamanho da partícula/abertura da peneira [m];

$\boldsymbol{x}_{\max }$ - tamanho máximo de partículas presente na distribuição [m];

$\boldsymbol{x}_{50}$ - tamanho mediano, no qual $50 \%$ das partículas da amostra passam [m];

$\boldsymbol{n}$ - agudez da distribuição [-].

Ao contrário da distribuição normal ou log-normal, o tratamento matemático dessa curva é mais simples.

Com relação à distribuição de tamanho de partículas, além de por si só ressaltar conceitos estatísticos aos alunos (como média, mediana, distribuição de frequência simples e acumulada), fomenta o uso de planilhas eletrônicas para os cálculos, com sua consequente interpretação gráfica. Além disso, pode-se relacionar isso a outras áreas que analisam informação diversificada em variadas classes distribuídas em quantidades distintas.

Outra propriedade muito importante é a massa específica (a qual se configura como uma propriedade intensiva, ou seja, independe da quantidade da amostra), que por sua vez possui sua importância no estudo de granéis, por exemplo, em sistemas de bombeamento de polpas minerais (suspensões aquosas de sólidos finamente cominuídos), onde a vazão de água no sistema dependerá das proporções das fases e de suas massas específicas. Também é uma característica que pode expressar a qualidade de insumos. Por exemplo: carvão vegetal para siderurgia necessita de madeiras de massa específica mais elevada, enquanto espécies de massa específica menor são utilizadas em fábricas de celulose de fibra curta (RIBEIRO \& ZANI FILHO, 1993).

A massa específica ( $\boldsymbol{\rho}$ ) (eventualmente chamada de baridade) de um corpo é dada pela conhecida relação entre a massa, $\boldsymbol{m}$, e o volume, $\boldsymbol{V}$, ocupado pelo corpo:

$$
\rho=\frac{m}{V}
$$

Cumpre ressaltar que há a tendência atual de chamar densidade $(\boldsymbol{d})$ à razão entre a massa específica do corpo e a massa específica da água a 277 kelvins $\left(4^{\circ} \mathrm{C}\right)$, isto é, uma grandeza adimensional dada por:

$$
d=\frac{\rho}{\left(\rho_{\mathrm{H}_{2} \mathrm{O}}\right)_{277 K}}=\frac{\rho}{1000}
$$

Uma diferença na definição de massa específica entre fluidos e sólidos granulares decorre do fato de que a relação entre a massa e o volume da substância ocupada, para granéis, é apenas uma massa específica aparente uma vez que existe a presença de vazios na amostra (espaço entre os grãos). A massa específica aparente do sólido é dada por: 


$$
\rho_{a p}=\frac{m}{V_{t}}=\frac{m}{V_{s}+V_{V}}
$$

Por seu turno, a consideração dos vazios existentes entre os grãos leva ao conceito de porosidade, que é a relação entre o volume de vazios $\left(\boldsymbol{V}_{\boldsymbol{v}}\right)$ e o volume total da amostra $\left(\boldsymbol{V}_{\boldsymbol{t}}\right)$. $A$ visualização da porosidade é mostrada na Figura 2, onde se percebe presença de volume não preenchido (volume de vazios) entre as partículas sólidas com volume total efetivo de sólidos $\left(\boldsymbol{V}_{\boldsymbol{s}}\right)$.

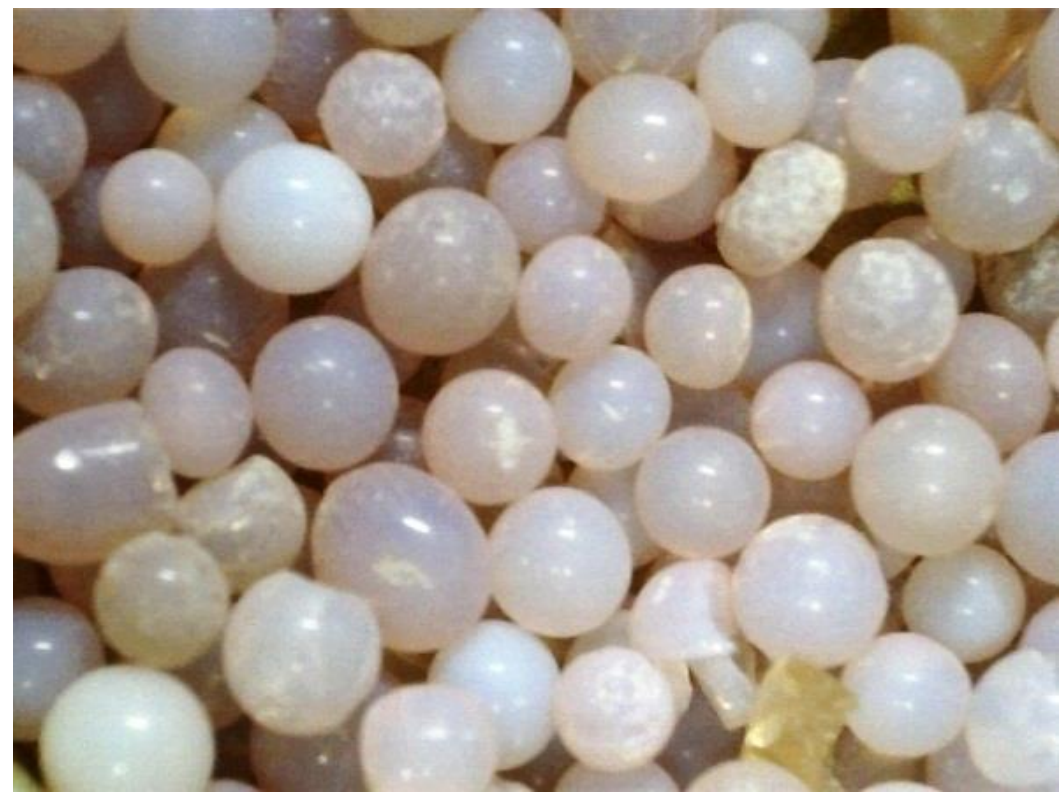

Figura 2: Ilustração da presença de vazios entre partículas milimétricas de sílica gel.

A partir dos valores de massa específica real e aparente, é possível encontrar a porosidade $(\boldsymbol{\varepsilon})$ do sistema, ou seja, a sua proporção de vazios. De forma geral, a porosidade é dada por:

$$
\varepsilon=\frac{\text { volume de vazios }}{\text { volume total }}=\frac{V_{V}}{V_{t}}=\frac{V_{V}}{V+V_{V}}
$$

É fácil deduzir, a partir desse conceito e do conceito de massa específica, que a porosidade pode ser obtida de modo simples no laboratório empregando-se a seguinte equação:

$$
\varepsilon=\frac{\rho_{\mathrm{s}}-\rho_{\mathrm{ap}}}{\rho_{\mathrm{s}}}
$$

Sendo $\boldsymbol{\rho}_{s}$ e $\boldsymbol{\rho}_{a p}$ as massas específicas real e aparente do sólido, respectivamente. Além disso, deve-se ter em mente que quanto maior o grau de compactação da amostra, menor será sua porosidade.

Como exemplo simples, facilmente realizável em sala, pode-se determinar porosidade de sistemas artificiais como, por exemplo, mesclando partículas de formato diverso, como indicado na Figura 3 seguinte, onde se veem granalhas esféricas $\left(\rho_{s}=7.839 \mathrm{~kg} / \mathrm{m}^{3}\right)$, cilindros $\left(\rho_{s}=7.790 \mathrm{~kg} / \mathrm{m}^{3}\right)$ e corpos discoidais com topo abaulado e fundo indentado em forma de pirâmide (comumente referidos como cílpebes - de cylindical pebble; $\boldsymbol{\rho}_{\mathrm{s}}=7.808 \mathrm{~kg} / \mathrm{m}^{3}$ ), todos de aço, mesclados. 


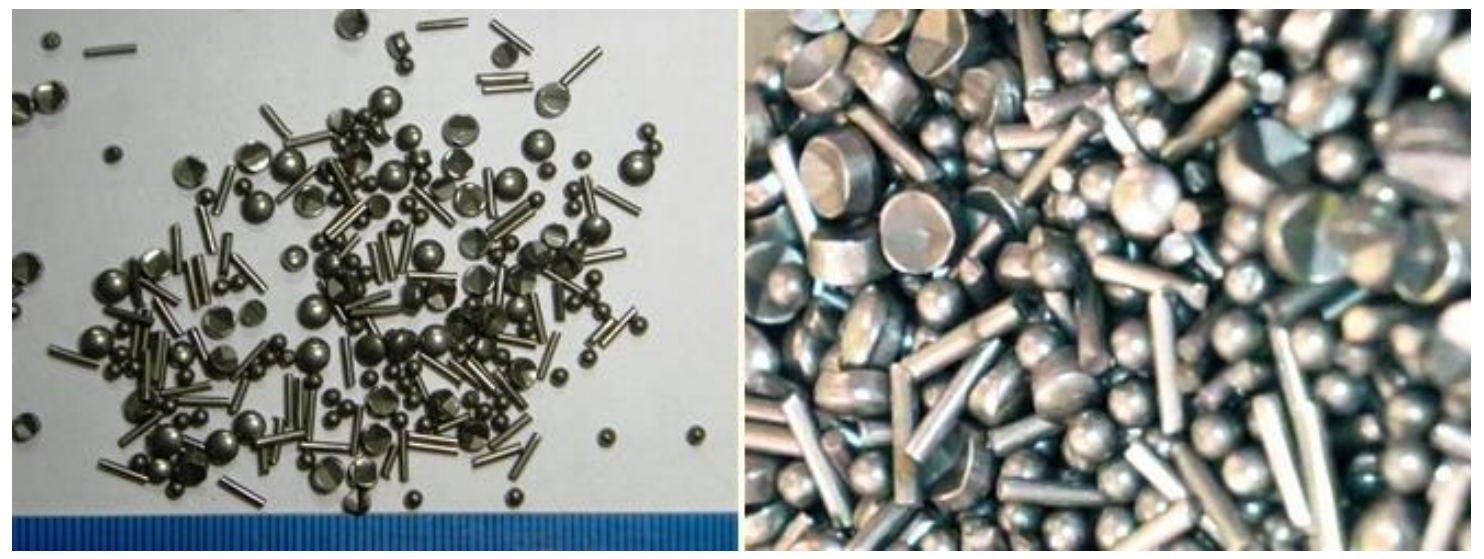

Figura 3: Exemplo de sistema sintético para cálculo de porosidade de misturas artificiais (as marcas da escala, na imagem à esquerda, referem-se a milímetros).

Tabela 1: Propriedades de sistemas particulados morfologicamente distintos (a compactação se refere a 20 quedas sucessivas do recipiente - proveta - desde a altura de 0,003 $\mathrm{m}$ sobre base de bancada emborrachada).

\begin{tabular}{|c|c|c|c|c|c|}
\hline \multirow{3}{*}{ Sistema } & \multicolumn{2}{|c|}{ Condição do sistema } & \multicolumn{2}{|c|}{ Porosidade } & \multirow{3}{*}{$\begin{array}{c}\text { Índice de } \\
\text { Hausner } \\
{[-]}\end{array}$} \\
\hline & frouxo & compactado & frouxo & compactado & \\
\hline & {$\left[\mathrm{kg} / \mathrm{m}^{3}\right]$} & {$\left[\mathrm{kg} / \mathrm{m}^{3}\right]$} & [\%] & [\%] & \\
\hline Esferas isoladas (tamanho: $2 \mathrm{~mm}$ ): & 4599,6 & 4637,9 & 41,32 & 40,84 & 1,01 \\
\hline Discoides isolados (tamanho: $3,5 \mathrm{~mm}$ ): & 4328,3 & 4443,7 & 44,57 & 43,09 & 1,03 \\
\hline Cilindros isolados (tamanho: $5,2 \mathrm{~mm}$ ): & 4570,7 & 4732,3 & 41,33 & 39,25 & 1,04 \\
\hline Esferas (40 \%) e discoides (60 \%): & 4482,9 & 4687,0 & 42,68 & 40,07 & 1,05 \\
\hline Esferas (54 \%) e cilindros (46 \%): & 3988,2 & 4278,9 & 48,98 & 45,26 & 1,07 \\
\hline $\begin{array}{c}\text { Discoides (64 \%) e cilindros (36 \%): } \\
\text { Esferas (30\%) e discoides (45\%) }\end{array}$ & 4399,5 & 4285,7 & 43,61 & 45,07 & 0,97 \\
\hline e cilindros (25\%): & 4531,3 & 4615,8 & 42,00 & 40,92 & 1,02 \\
\hline
\end{tabular}

Em Valadares e Luz (2004), foram apresentadas várias razões que tornam importante o conhecimento da porosidade em sistemas polidispersos, a saber: na estimação da pressão adequada que atenda a uma dada taxa de filtragem de sólidos; no conhecimento dos grãos que constituem a rocha hospedeira de um arenito petrolífero; no conhecimento da porosidade da mistura de sínter, permitindo o dimensionamento de ventiladores e exaustores das máquinas de sinterização e na flotação (processo a úmido de enriquecimento de materiais particulados por hidrofobização seletiva), onde conhecer a porosidade da espuma permite estimar a vazão de polpa hidrofílica, de forma a não prejudicar o fluxo de concentrado hidrofóbico carreado pela espuma. Por seu turno, Prado e Luz (2016) obtiveram uma equação de regressão para a previsão da porosidade de sistemas esferoidais polidispersos densificados bem descritos por uma distribuição de Rosin-Rammler. Essa equação exponencial, em função da agudez da distribuição ( $\boldsymbol{n}$ ), apresentou coeficiente de correlação 0,9753 e é expressa por:

$$
\varepsilon(n)=0,2204 \times\left[1-e^{-\left(\frac{n}{1,1426}\right)^{1,419}}\right]+0,1504
$$


Um dos fatores que influencia na porosidade dos sólidos é a forma das partículas. Outras características influenciadas pela forma são: interação com fluidos, empacotamento, poder de cobertura de pigmentos em tintas e coesão entre as partículas, dentre outros (ALLEN, 1997).

A importância da forma das partículas pode ser exemplificada na construção civil: partículas mais irregulares demandam mais cimento, onerando o custo do concreto. Por outro lado certo grau de irregularidade pode promover maior amarração do agregado à matriz de cimento Portland.

Em operações de peneiramento, por sua vez, as partículas de forma irregular propiciam menor entupimento das aberturas da tela da peneira, quando comparadas com partículas esféricas (ROBERTS \& BEDDOW, 1969). Assim, partículas irregulares podem se desatar das aberturas, quando mal ajustadas nas mesmas, e serem reapresentadas à área da peneira, sob um ângulo mais adequado à sua passagem. Isto propicia um processo de separação mais eficiente entre as várias distribuições de tamanho das partículas.

Um parâmetro muito utilizado para análise da morfologia de partículas é a esfericidade proposta por Wadell (1932). Este parâmetro consiste na razão entre a área superficial de uma esfera e a área superficial da partícula, ambas com volumes equivalentes. Assim, a esfericidade de Wadell é dada por:

$$
\psi=\frac{\text { área da esfera de mesmo volume }}{\text { área da partícula de mesmo volume }} \leq 1
$$

Para uma mesma distribuição granulométrica, a porosidade e a esfericidade são opostamente relacionadas: meios granulares com partículas esféricas são menos porosos, devido ao melhor arranjo e empacotamento das mesmas no leito.

As características dos sólidos particulados também podem ser analisadas de acordo com sua reologia, que também é dependente da forma e distribuição de tamanhos das partículas. Dentre as análises reológicas executáveis em granéis, citam-se aqui aquelas relativas ao escoamento e atrito entre partículas, que são características que mudam de acordo com o empacotamento das mesmas. Uma dessas características é o índice de Hausner, o qual está ligado à angulosidade entre coeficiente de atrito das partículas. O seu conhecimento permite, assim, descrever o grau de empacotamento e a escoabilidade do granel. Trata-se de uma propriedade importante, que possibilita avaliar, conforme mencionado por Guo et alii (1985), a estocagem de sólidos em silos ou prever o tempo até que a peneira atinja o pico de entupimento das telas (ROBERTS \& BEDDOW, 1969).

Esse índice é a razão entre a massa específica compactada e a massa específica aparente da amostra. Assim, um sistema granular que possua elevado índice de Hausner apresentará difícil mobilidade (escoamento). Isto implicará na necessidade de utilização de substâncias lubrificantes que promovam a escoabilidade do granel.

Valores limites de índice de Hausner podem ser encontrados na Tabela 2.

O escoamento por gravidade de material granular ou particulado é comum em muitas instâncias da indústria extrativa. O escoamento do material em um silo depende da sua geometria, da natureza das partículas, da modalidade de retomada do material e das condições ambientais, entre outros fatores. 
Tabela 2: Índice de Hausner (IH) e escoabilidade do meio granular.

\begin{tabular}{c|c}
\hline IH & Escoamento \\
\hline$<1,25$ & Fácil \\
1,25 a 1,5 & Necessita lubrificante \\
$>1,5$ & Muito difícil \\
\hline
\end{tabular}

A quantificação das propriedades que afetam o comportamento dos sólidos quando estocados e descarregados de silos pode nortear a especificação adequada da geometria do silo. Trabalho anterior realizado por Luz e Silva (2002) se inseriu nesse contexto e estudou o efeito sobre o escoamento de particulados de parâmetros do sistema, como: abertura relativa da saída do silo, método de extração ou retomada, morfologia e densidade das partículas, altura da coluna de material granular e ângulo de atrito interno. Milhomem e Luz (2013) já analisaram a escoabilidade de granéis levando-se em conta a umidade (a baixos níveis) e tensão interfacial da fase aquosa, verificando que tais alterações no sistema influenciam o escoamento do material.

Por fim, outra característica analisada e de igualmente fácil mensuração foi o ângulo de repouso dinâmico do sistema, relacionado ao atrito e rolamento entre os grãos, e que também possibilita ter noção da fluidez do sistema. Neste caso, a sua medição é feita ao se formar uma pilha de material despejado numa superfície livre e plana.

\section{METODOLOGIA E RESULTADOS}

Areia e esférulas de vidro foram utilizadas para a realização dos experimentos. $O$ aparato necessário para os ensaios é relativamente simples e a reprodutibilidade mostrou-se aceitável.

Antes da realização dos ensaios de peneiramento, as amostras foram homogeneizadas separadamente. Tal técnica consiste em fazer com que a amostra apresente suas propriedades (como a distribuição de tamanhos) o mais uniformemente possível em toda a sua extensão. Isto é necessário em virtude da estratificação que tende a ocorrer no seio do material granular, durante seu manuseio. Os finos tendem a ir para o fundo (por passarem mais facilmente pelos interstícios) e os grossos para as bordas do sistema. Esse último fenômeno ocorre em consequência de as maiores partículas possuírem maior quantidade de movimento (produto da massa por velocidade), o que leva as mesmas a se distribuírem em pontos mais distantes do centro da pilha da amostra. Isso é comumente observado em pilha de material particulado (cônica ou longitudinal).

Para a realização da homogeneização do material, foi realizado o chamado método da pilha cônica. Nele, a amostra é disposta no centro de uma lona quadrada (ou outro elemento semelhante). As dimensões da lona devem ser suficientes para permitir que os seus vértices sejam movimentados alternativamente, fazendo o rolamento do material na superfície da lona, sem, no entanto, ocasionar sua perda por derramamento. Cada vértice da lona é levantado alternadamente, provocando o revolvimento do material e fazendo o material da base ser sobreposto ao de topo, conforme sugerido na Figura 4. Foram realizadas quarenta contagens (revolvimentos) desta forma. Uma vez homogeneizadas, as amostras puderam ser utilizadas nos demais ensaios. 


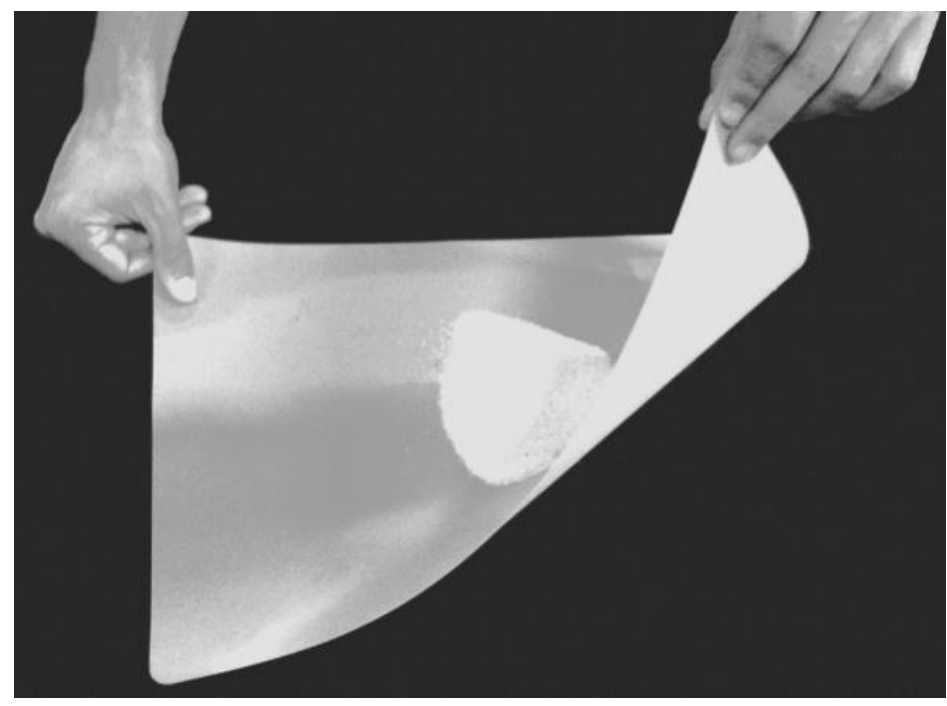

Figura 4: Processo de homogeneização por pilha cônica.

A distribuição de tamanho das partículas pode ser realizada através da análise granulométrica. Ela possibilita conhecer a frequência com que as partículas ocorrem em dada faixa de tamanho.

Esta determinação de tamanhos pode ser realizada por diferentes técnicas, que vão desde a análise da sedimentação do sólido em líquido estacionário (cujas partículas sedimentarão em maior ou menor velocidade, de acordo com seu tamanho e morfologia); análise de espalhamento de luz pelas partículas (empregando-se granulômetro a laser); atuação de forças centrífugas em meio líquido (sedimentação centrífuga); análise por microscopia; ou mesmo através do peneiramento, que consiste em fazer com que as partículas, quando exequível, passem através de uma série de peneiras de diferentes aberturas, propiciando assim uma barreira física à sua passagem, com gradual redução nas aberturas das peneiras. $O$ último método é o mais comumente aplicado, em virtude de sua simplicidade, abrangência de tamanhos e rápido diagnóstico. Os resultados podem ser facilmente visualizados através de programas como planilhas eletrônicas ou pacotes específicos (a exemplo do EasyPlot e do Scilab). Além disso, o método pode tanto ser automatizado, utilizando-se peneirador vibratório, como manual.

A seguir à homogeneização, a amostra era disposta na peneira superior. Naturalmente, a abertura das peneiras decresce da superior até a inferior, a qual se assenta sobre a panela de fundo (abertura nominal igual a zero). O método foi automatizado (utilização de vibrador, embora o peneiramento manual também possa ser levado a cabo, sem maiores problemas) e realizado presença de água (adicionada na peneira superior ao longo do experimento). Com relação a este aspecto, salienta-se a importância da umidade no sistema: se ela estiver tipicamente dentro da faixa de valores entre $5 \%$ e $20 \%$, efeitos interfaciais propiciarão a coesão entre as partículas, podendo fazer com que e as mesmas se movimentem como blocos ou agregados sobre a peneira. Isto ocasiona baixa eficiência do processo, conforme pode ser visualizado na Figura 5. Assim, o ideal é que o peneiramento seja realizado ou a seco, ou com grande quantidade de água (acima de $60 \%$ ), para facilitar a movimentação e a passagem das partículas finas pela abertura da peneira. 


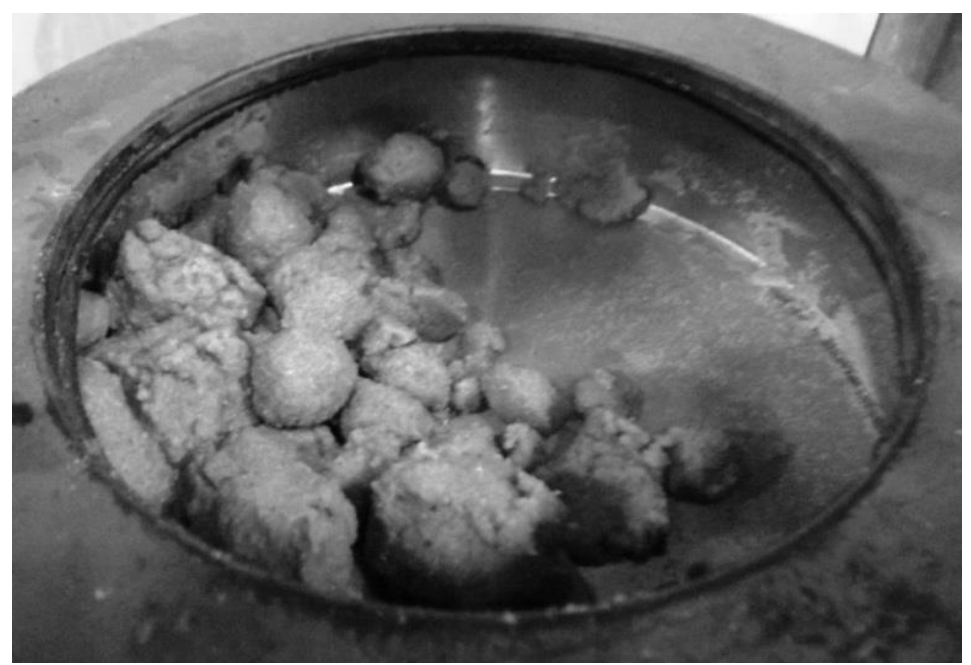

Figura 5: Formação de grumos (partículas ligadas por pontes líquidas com elevada tensão superficial) sobre a superfície da peneira quando do uso de pouca água.

O tempo de peneiramento não foi pré-estabelecido, sendo o mesmo realizado até o momento em que a água passante na última peneira não estava mais turva, indicando que não havia mais material que pudesse passar pela última peneira. Para peneiramento manual (com movimentos oscilatórios vigorosos) o mesmo critério deve ser seguido.

Deve-se observar que as propriedades morfológicas dos granéis são geralmente dependentes de muitas variáveis, mas com prevalência de algumas delas (como por exemplo, a clivagem, o faturamento preferencial em dados planos cristalinos, a tendência a se cominuírem as partículas maiores dentro de britadores ou moinhos, etc.).

Na Tabela 3 está o algoritmo de quantificação da análise, expressando os valores em base percentual. O retido simples representa a quantidade absoluta (em percentagem) que ficou retida na peneira daquele tamanho $\mathrm{dn}$. O retido acumulado representa a porcentagem de material que se encontra em tamanho maior ou igual àquele da peneira em análise (ou seja, considera também os retidos das peneiras superiores), e o passante acumulado representa a quantidade total de material que há menor que aquela abertura de peneira. Percebe-se que se trata de uma tabela simples, podendo ser facilmente implementada em planilhas eletrônicas.

Tabela 3: Cálculos para análise granulométrica.

\begin{tabular}{|c|c|c|c|c|}
\hline $\begin{array}{c}\text { Tamanho } \\
{[\mathrm{mm}]}\end{array}$ & Massa [g] & Retido simples [\%] & Retido acumulado [\%] & $\begin{array}{c}\text { Passante acumulado } \\
{[\%]} \\
\end{array}$ \\
\hline $\mathrm{d}_{1}$ & $\mathrm{~m}_{1}$ & $\mathrm{R}_{1}=\left(\mathrm{m}_{1} / \mathrm{m}_{\mathrm{t}}\right) \times 100$ & $\mathrm{RA}_{1}=\mathrm{R}_{1}$ & $P_{1}=100-R A_{1}$ \\
\hline$d_{2}$ & $\mathrm{~m}_{2}$ & $\mathrm{R}_{2}=\left(\mathrm{m}_{2} / \mathrm{m}_{\mathrm{t}}\right) \times 100$ & $R A_{2}=R A_{1}+R_{2}$ & $P_{2}=100-R A_{2}$ \\
\hline$\ldots$ & $\ldots$ & $\ldots$ & & $\ldots$ \\
\hline$d_{n}$ & $m_{n}$ & $R_{n}=\left(m_{n} / m_{t}\right) \times 100$ & $R A_{n}=R A_{n-1}+R_{n}$ & $P_{n}=100-R A_{n}$ \\
\hline$[-]$ & $\sum_{i=1} m_{t}$ & $\sum_{i=1} \mathrm{R}_{\mathrm{t}}$ & {$[-]$} & {$[-]$} \\
\hline
\end{tabular}

Ao contrário da distribuição normal ou log-normal, o tratamento matemático dessa curva é simples. Na Figura 6 está mostrada a construção da curva de distribuição granulométrica. 0 tamanho de partículas se encontra no eixo das abscissas e o passante acumulado no eixo das ordenadas. $O$ passante acumulado em dada peneira é a quantidade passante se fossem retiradas as peneiras superiores a ela (de maior abertura). 


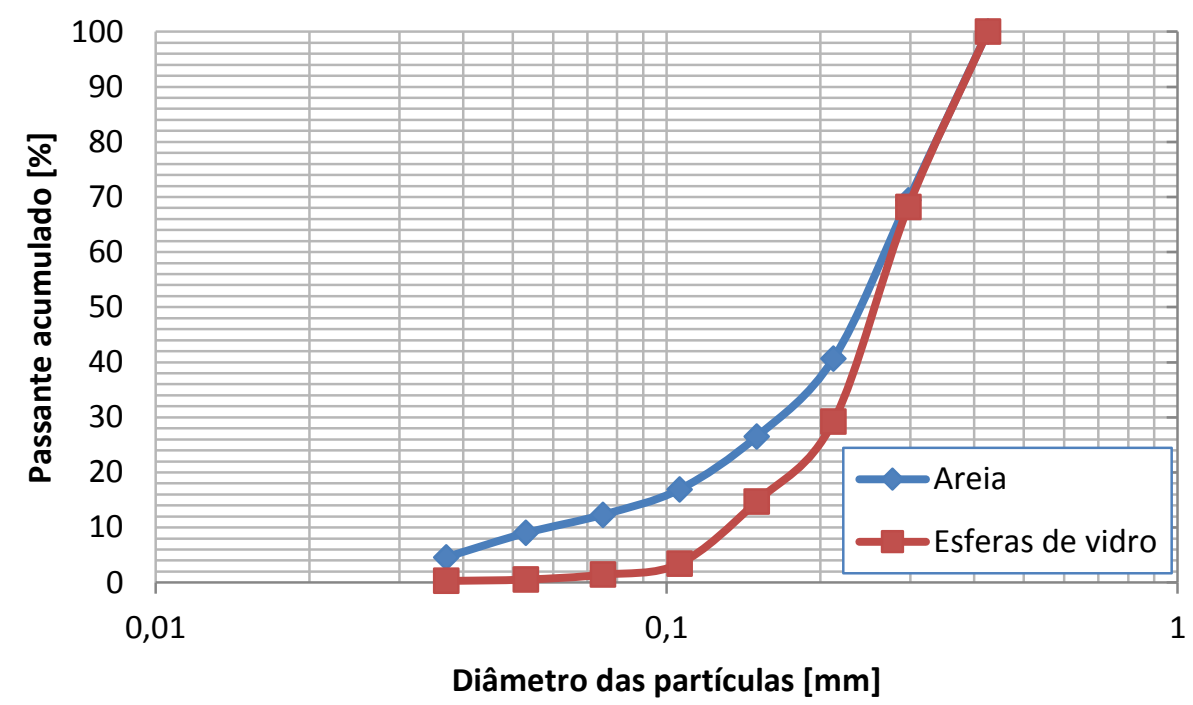

Figura 6: Distribuição de tamanho das partículas de areia e de esferas de vidro.

Como o peneiramento possibilitou separar as partículas em tamanhos distintos, escolheuse para a realização dos ensaios o tamanho de partículas inferior a $425 \mu \mathrm{m}$.

Os ensaios para determinação da massa específica real foram realizados através de picnometria. Para a execução deste teste, um picnômetro vazio, de $50 \mathrm{ml}$ foi pesado. Para tal massa foi atribuído o valor $m_{1}$ (massa do picnômetro vazio).

Em seguida o picnômetro foi preenchido com cerca de $20 \%$ de seu volume, e pesado. Obteve-se o valor de $m_{2}$ (massa do picnômetro + massa da amostra). A seguir, adicionou-se água no picnômetro até o mesmo ser completamente preenchido, tomando o cuidado de se enxugar com papel absorvente qualquer transbordo no lado externo do picnômetro. O novo conjunto foi pesado novamente, obtendo-se $m_{3}$ (massa do picnômetro + massa da amostra + massa de água). Por fim, o picnômetro foi esvaziado e preenchido apenas com água, tendo-se assim $\mathrm{m}_{4}$ (massa do picnômetro + massa de água).

Com os valores de $m_{1}, m_{2}, m_{3}$ e $m_{4}$, foi possível encontrar a massa específica real do sólido, conforme a fórmula a seguir (para um sistema coerente de unidades):

$$
\rho_{\mathrm{s}}=\frac{\left(\mathrm{m}_{2}-\mathrm{m}_{1}\right) \times \rho_{\mathrm{H}_{2} \mathrm{O}}}{\left(\mathrm{m}_{4}+\mathrm{m}_{2}\right)-\left(\mathrm{m}_{1}+\mathrm{m}_{3}\right)}
$$

No adendo A, encontra-se a dedução da equação anterior.

A massa específica aparente foi determinada colocando-se massa conhecida do sistema particulado em proveta graduada e mensurando-se o volume. Os valores encontrados para a areia e para as esferas de vidro são mostrados na Tabela 4.

Tabela 4: Resultados caracterização das amostras

\begin{tabular}{c|c|c|c}
\hline Material & Massa específica real $\left[\mathrm{kg} / \mathrm{m}^{\mathbf{3}}\right]$ & Massa específica aparente $\left[\mathrm{kg} / \mathrm{m}^{\mathbf{3}}\right]$ & Porosidade $[-]$ \\
\hline Areia & 2.690 & 1.520 & 0,430 \\
Esferas & 2.480 & 1.480 & 0,632 \\
\hline
\end{tabular}


Os ensaios de compactação das amostras foram realizados em proveta de 0,5 I onde se verteu aproximadamente 0,4 I de sólido. Após leitura do nível inicial na graduação volumétrica da proveta, a mesma era então submetida a sucessivos impactos, ocasionados por quedas (devidas unicamente à gravidade) sobre superfície plana e emborrachada. A altura utilizada para a queda da proveta foi de $0,03 \mathrm{~m}$ da superfície. O volume ocupado pelos sólidos após determinada quantidade de impactos era medido, fazendo-se a leitura do nível de granel na escala da proveta. Mediu-se a evolução do volume aparente ocupado na proveta desde o início (zero impacto) até 200 impactos. A partir desse valor, as amostras não mais apresentavam mudança no volume, encerrando-se assim o experimento.

Utilizando o volume de material compactado, e pesando-se a massa utilizada no ensaio, foi possível encontrar a massa específica compactada. Dividindo-se a massa específica compactada pela aparente, encontrou-se o índice de Hausner. A areia estudada acusou índice de Hausner de 1,05 e as esférulas de vidro apresentaram valor de 1,01.

Para a avaliação da esfericidade das partículas, utilizou-se a escala de Krumbein. Segundo Drevin e Vincent (2002), a esfericidade pode ser estimada através de simples análise visual, comparando a forma das partículas com a forma mais semelhante presente na escala.

A análise comparativa entre as fotografias e a escala de Krumbein (apresentada na Figura 7 a seguir) indicou os valores de esfericidade de 0,75 para a areia, e de 0,98 para as esférulas de vidro.

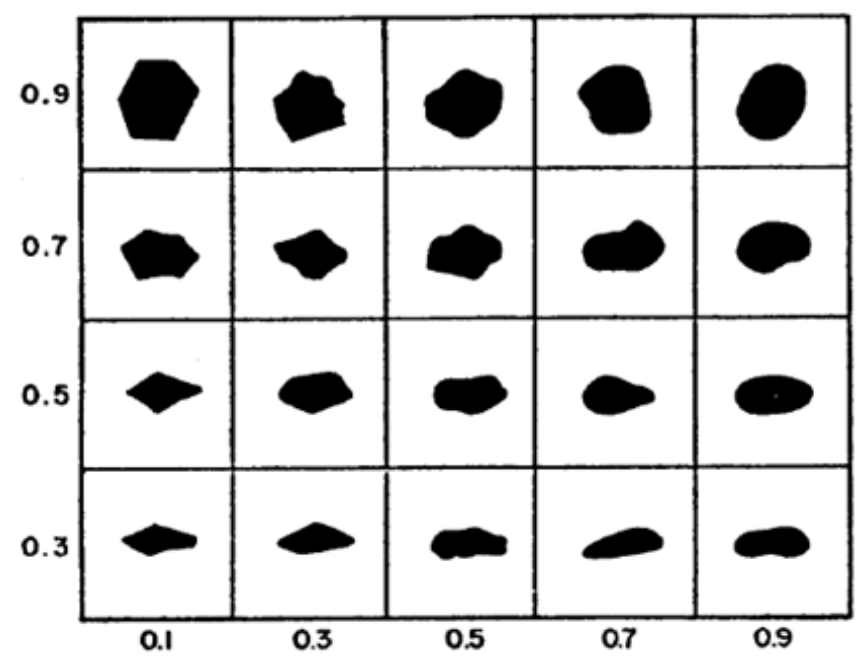

Figura 7: Escala de Krumbein para determinação visual da esfericidade de partículas (o eixo vertical refere-se aos valores de esfericidade e o horizontal, ao grau de arredondamento).

Na Figura 8, encontram-se microfotografias das amostras utilizadas para a comparação visual. Foi utilizado microscópio digital com conexão USB, de baixo preço (facilmente adquirível pela Internet, com preço típico por volta de US\$ 60.00). 


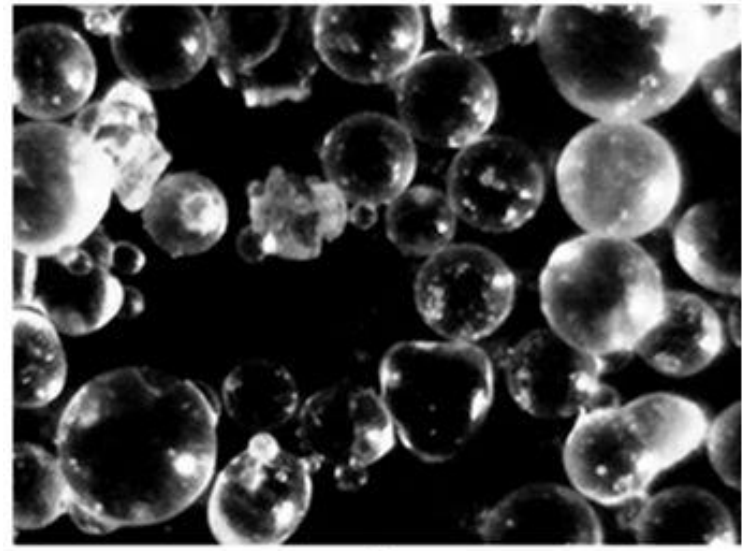

(a)

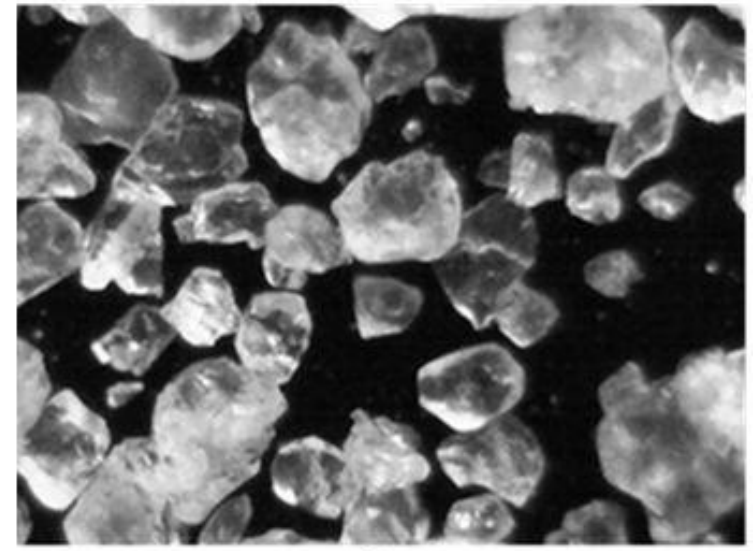

(b)

Figura 8: Amostras utilizadas nos ensaios: (A) esférulas de vidro; (B) areia.

Por fim, foram realizados os ensaios para medição da velocidade de escoamento e o ângulo de repouso dinâmico. Foi utilizado um silo, conforme mostrado na Figura 9, e cujas dimensões se encontram na Tabela 5. O silo era preenchido com os granéis até a cota de 0,132 $\mathrm{m}$ acima do orifício inferior, inicialmente obturado. Em seguida, tal orifício era liberado para o escoamento e o cronômetro, acionado. Amostras eram coletadas, manualmente, a cada 3 segundos, utilizando-se copos descartáveis. Com isso, era possível quantificar o escoamento do granel em cada intervalo de tempo. Vale ressaltar que um sistema automatizado simples também pode ser utilizado para esse tipo de análise, conforme trabalho semelhante (para análise do escoamento de materiais granulares) apresentado por Lopez et alii (2012).

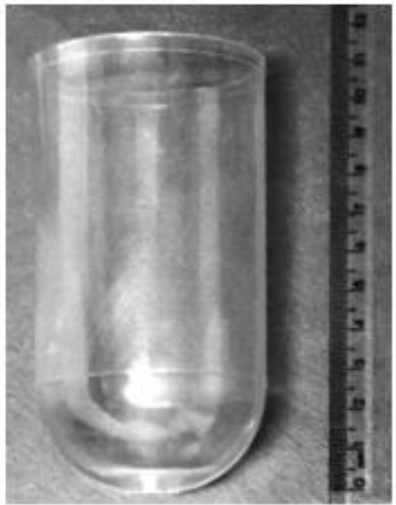

(a)

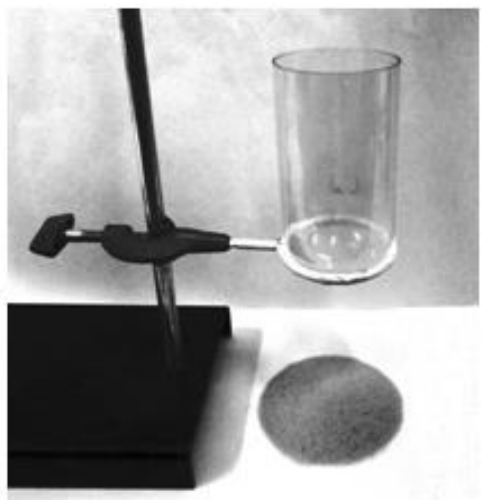

(b)

Figura 9: Aparato utilizado nos ensaios - a) silo; b) montagem do suporte com o silo.

Tabela 5: Características do silo utilizado nos ensaios

\begin{tabular}{ll}
\hline \multicolumn{2}{c}{ Dimensões do silo [m] } \\
\hline Altura total & $1,36 \times 10^{-01}$ \\
Altura útil & $1,32 \times 10^{-01}$ \\
Diâmetro interno & $5,61 \times 10^{-02}$ \\
Altura da parte cilíndrica & $8,18 \times 10^{-02}$ \\
Flecha do elipsoide oblato & $2,50 \times 10^{-02}$ \\
Diâmetro interno do orifício & $8,10 \times 10^{-03}$ \\
\hline
\end{tabular}


O comportamento das amostras no escoamento pode ser visualizado na Figura 10.

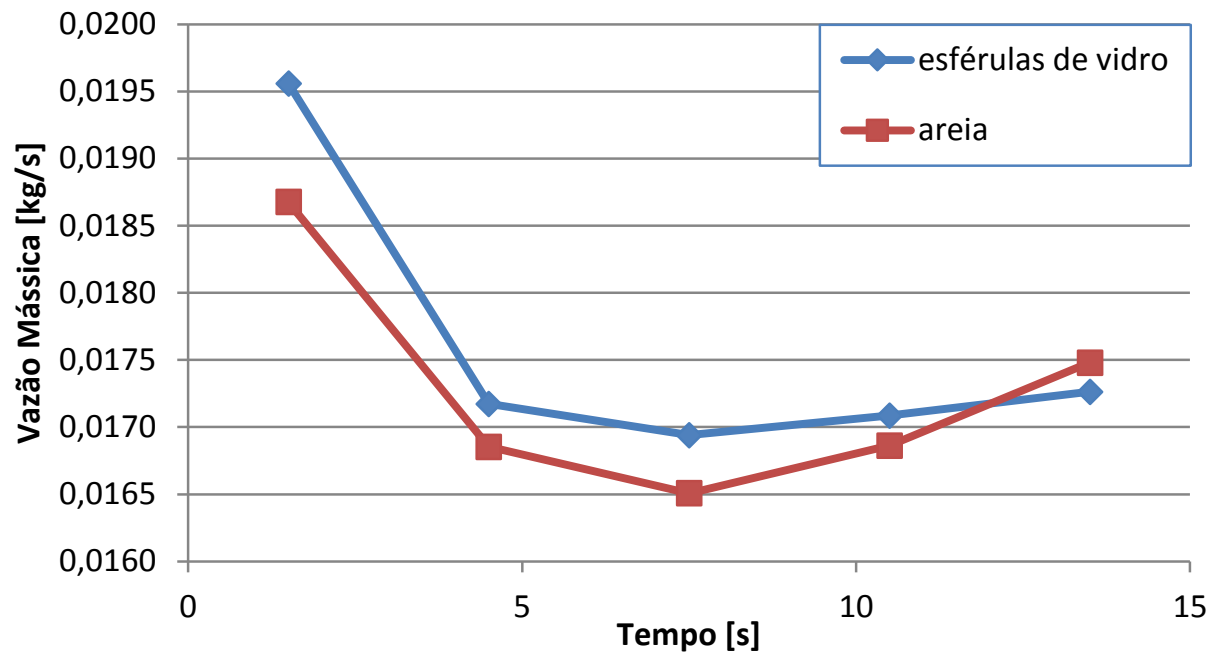

Figura 10: Comportamento das amostras no escoamento.

Percebe-se comportamento semelhante em ambas as amostras, com elevada vazão inicial, que decresce no decorrer da operação, mas que aumenta novamente nos instantes finais, sugerindo a ocorrência de complexos fenômenos reológicos, para além do escopo do presente artigo.

Ensaios de escoamento com fluido viscoso (óleo de soja) também foi executado, visando a comparar o escoamento entre granéis e fluidos. O mesmo silo dos ensaios anteriores foi utilizando nessa instância e empregando-se cronômetro manual. A escolha do óleo (o qual possuía a viscosidade dinâmica igual a 0,063 Pa.s a $22^{\circ} \mathrm{C}$ ), deveu-se a exequibilidade das medidas de tempo (uma vez que o tempo de escoamento da água era demasiado rápido para permitir medidas acuradas). Na Figura 11 encontra-se a comparação entre os ensaios entre granéis e o fluido viscoso.

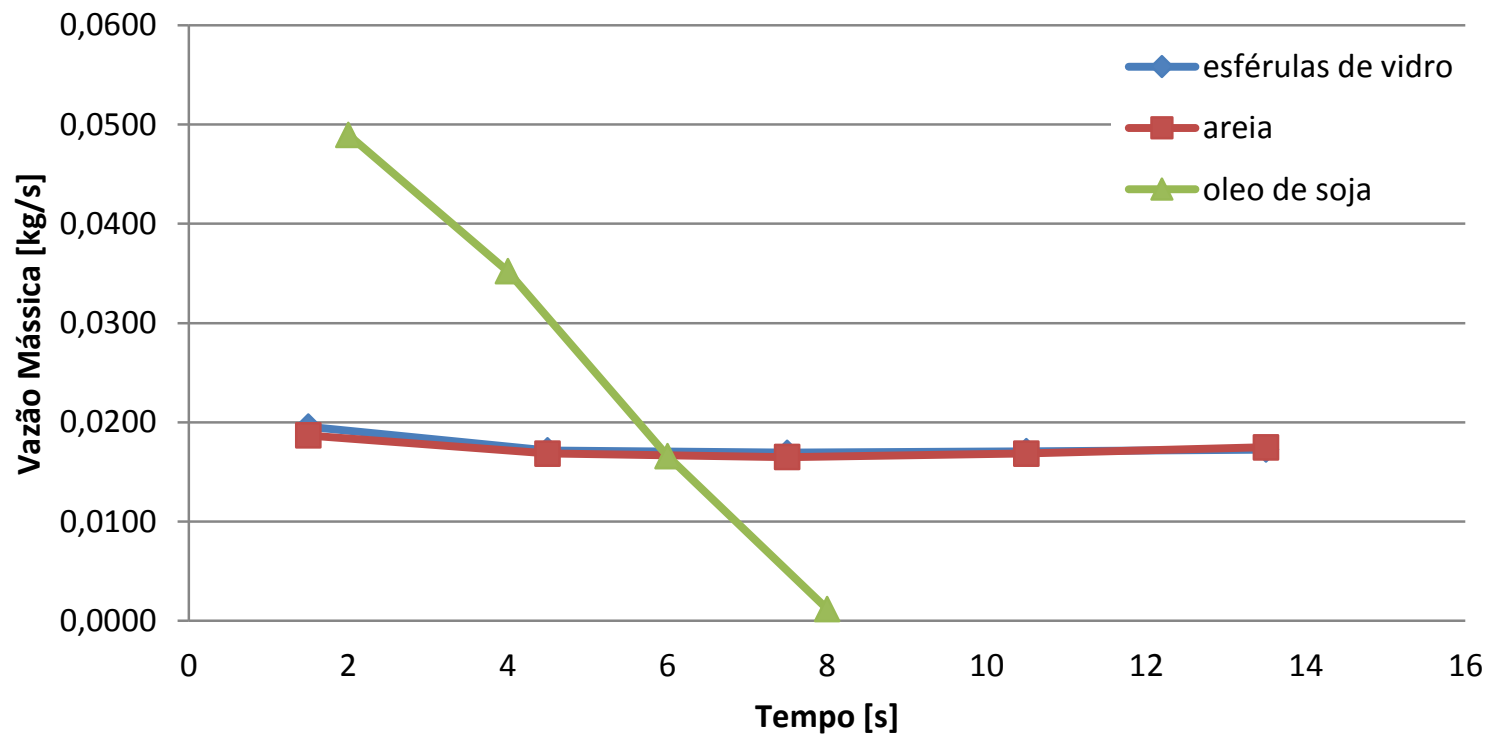

Figura 11: Comparação entre o escoamento entre granéis e óleo de soja.

Dentro do estudo de granéis, o ângulo de repouso das amostras também pode ser facilmente medido. No caso em tela, a amostra era despejada pelo silo em uma superfície plana e lisa, formando pilha de material particulado. Em seguida, a altura e o diâmetro da pilha eram 
medidos com o emprego de réguas. Na mensuração do diâmetro, eram tomadas no mínimo quatro direções e adotado o valor médio. $O$ ângulo de repouso (dinâmico) é aquele cuja tangente é igual a razão $(\boldsymbol{h} / \boldsymbol{r})$. A Figura 12 apresenta o aparato para mensuração do ângulo de repouso dinâmico, com formação da pilha de material.Na Tabela 6 estão mostrados os valores usuais de ângulo de repouso dinâmico e o tipo de escoamento do produto. O ângulo acusou $25,88^{\circ}$ para as esferas de vidro, ao passo que para areia ângulo de repouso dinâmico de $28,77^{\circ}$ foi obtido. Como os ângulos são menores que $30^{\circ}$ indicam bom escoamento para ambos os materiais.

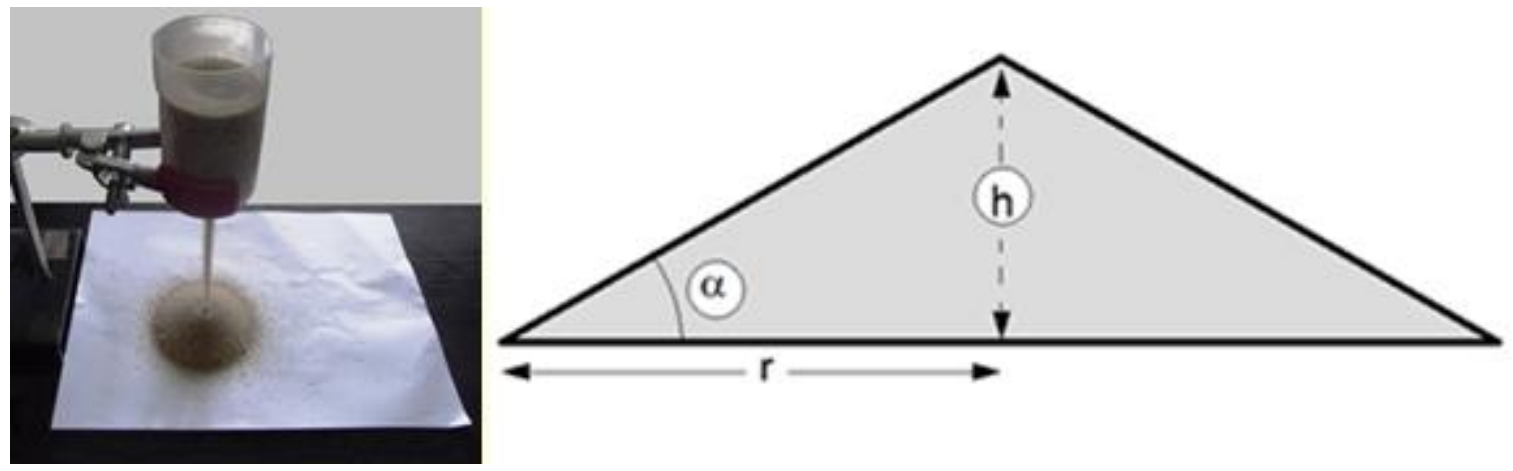

Figura 12: Obtenção do ângulo de repouso dinâmico (visto que os grânulos estavam munidos movimento de queda, e, portanto, interagiam por atrito dinâmico, menor do que o atrito estático) da pilha de material particulado.

Tabela 6: Tipo de escoamento de acordo com o ângulo de repouso.

\begin{tabular}{c|c}
\hline Ângulo de repouso $\left[^{\circ}\right]$ & Produto/Tipo de escoamento \\
\hline 25 a 30 & Granular/escoamento livre \\
30 a 38 & Granular/escoamento fácil \\
38 a 45 & Pulverulento/instabilidade no tipo de escoamento \\
45 a 55 & Pó coesivo/pode requerer equipamento especial \\
55 a 70 & Pó muito coesivo/requer equipamento especial \\
\hline
\end{tabular}

\section{CONCLUSÕES}

Foram propostas atividades extracurriculares de fácil execução, através de experimentos de aparato simples, de fácil reprodutibilidade e de fácil análise a partir do estudo dos sistemas particulados densificados, conhecidos por granéis, que estão largamente presente no nosso dia a dia. Tais atividades podem ser executadas junto a alunos de graduação ou mesmo do segundo grau, levando-os à contextualização de diversos conceitos matemáticos e físicos no mundo real.

Vale ressaltar que a ubiquidade de tais sistemas esconde uma complexidade alta, que aparece quando se tornam objeto de estudo. A população de partículas que formam um desses sistemas é em larga medida o aspecto definidor desse comportamento. Aspectos morfológicos das partículas, sua distribuição granulométrica, seu nível de compactação, atrito e fenômenos de superfície (como tensão superficial), são relevantes.

Uma coisa é a dedução fenomenológica de equações ligadas aos preceitos matemáticos e fenômenos físicos; outra - a qual é, afinal, mais profícua em resultados - é a incorporação desse conhecimento aplicado em instâncias concretas deste fascinante mundo em que vivem os 
hominídeos modernos, munidos de ideação simbólica e linguagem escrita (aspectos que nos fazem tão peculiares, em termos de coletividade animal).

Ademais, esses experimentos apresentam-se como excelente oportunidade para se realizarem tarefas dentro do conceito educacional de transversalidade. Por exemplo, embora não tenham sido explorados, nesse sentido, aqui, os resultados podem servir de base para o estudo da teoria estatística dos erros. Isso, em nível de ensino médio, pode ser feito com o cálculo de média, desvio padrão, coeficiente de variação, e cálculo das incertezas das mensurações experimentais.

Os experimentos ainda podem ser enriquecidos ao utilizar corpos de diferentes formatos, tal qual mostrado aqui, com cilindros, cílpebes e esférulas. Com isso, as diferenças entre os corpos reais e aqueles ditos ideais (comumente utilizados nos exemplos de sala de aula) podem ser ressaltadas com exemplos práticos e que na realidade, a forma das partículas influencia os diversos processos aos quais são submetidas.

Além disso, conceitos físicos como de atrito (estático e dinâmico) podem ser evidenciados ao se analisar o escoamento do sistema particulado através do índice de Hausner, porosidade e ângulo de repouso assim como a importância dele na coesão de pilhas de granel. No caso do estudo de pilhas de material, a influência da quantidade de movimento pode ainda ser discutida ao se analisar a distribuição de tamanhos de material no centro e nas bordas da mesma (o fenômeno da segregação granulométrica).

É possível também trabalhar conceitos de distribuição de frequência estatística, mostrando a tendência de os erros experimentais (quando isentos de viés estatístico) seguir distribuição normal de Gauss, em contraste com outras distribuições que melhor descrevem sistemas particulados, em especial à de Rosin-Rammler (caso particular da equação de Weibull) aqui utilizada.

Por fim, e não menos importante como ferramenta de despertar do senso crítico, ressaltese a comparação entre sistemas sólidos e líquidos, no que tange a sua cinética de escoamento gravitacional.

\section{AGRADECIMENTOS}

Um dos autores (J. A. M. L.) agradece ao Conselho Nacional de Pesquisa - CNPq (Brasil) pelo suporte na forma de bolsa de produtividade em pesquisa.

\section{REFERÊNCIAS BIBLIOGRÁFICAS}

1. ALLEN, T. Particle Size Measurement (5th ed). London: Chapman and Hall, 1997. 525 p.

2. BERTEL INDÚSTRIA METALÚRGICA LTDA. Peneiras granulométricas (tamis): Catálogo de produtos. Disponível em: http://www.bertel.com.br/peneira.html. Acesso em: 12 jun. 2015.

3. DREVIN, G. R.; VINCENT, L. Granulometric Determination of Sedimentary Rock Particle Roundness. In: Proceedings of the International Symposium on Mathematical Morphology, Sidney, Australia, 2002, p. 1 - 10.

4. GUO, A.; BEDDOW, J. K.; Vetter, A. F. A. Simples Relationship Between Particle Shape Effects and Density, Flow Rate and Hausner Ratio. Powder Technology, v. 43, p. 279-284, 1985. 
5. LOPEZ, J.; PASTORELLO, I. M.; ARCE, A.I.C. Vazão de grãos em um silo cilíndrico: uma atividade experimental. Revista Brasileira de Ensino de Física, v. 34, n.4, 4308, 2012.

6. LOPEZ, J.; VERCIK, A.; COSTA, E. J. X. Meios granulares e experimentos simples para a sala de aula. Revista Brasileira de Ensino de Física, v. 30, n. 1, 1308, 2008.

7. LUZ, J. A. M.; SILVA J. M. Fluxo de material particulado em sistemas confinados. In: XIX ENTMME Encontro Nacional de Tratamento de Minérios e Metalurgia Extrativa ENTMME, Recife. Anais... Recife: 2002, p 381-388.

8. MILHOMEM, F. O.; LUZ, J. A. M. Escoabilidade de graneis úmidos. In: XXV Encontro Nacional de Tratamento de Minérios e Metalurgia Extrativa - ENTMME, Goiânia. Anais... Goiânia: 2013, p. 491-498.

9. PRADO, D. R.; LUZ, J. A. M. On Bed Porosity of Multisized Spheroidal Particles. Artigo submetido a: Chemical Engineering Research and Development (under review, 2016).

10. RIBEIRO, F. A. E.; ZANI Filho, J. Variação da densidade básica da madeira em espécies/procedências de Eucalyptus sp. IPEF, n.46, p.76-85, jan./dez. 1993.

11. ROBERTS, T. A.; BEDDOW, J. K. Some Effect of Particle Shape and Size upon Blinding During Sieving. Powder Technology, 2, p. 121-124, 1968/69.

12. SMITH, M. Determination of the density of crystalline germanium. In: SHOEMAKER, D. P.; GARLAND,C. W; NIBLER, J. W. Experiments in Physical Chemistry, Sixth Edition. New York: McGraw-Hill, 1996. xii + 778 pp. ISBN 0-07-057074-4.

13. VAlADARES, T. N.; LUZ, J. A. M. Porosidade de Sistemas Polidispersos Compactados. In: XX Encontro Nacional de Tratamento de Minérios e Metalurgia Extrativa - ENTMME, 2004, Florianópolis. Anais... Criciúma: UNESC, 2004. V. 2. p. 235-242.

14. WADELL, H. Volume, shape, and roundness of rock particles. Journal of Geology, 40: 443-51, 1932. 


\section{ADENDO A: DEDUÇÃO DA EQUAÇÃO 9}

(Massa específica por picnometria)
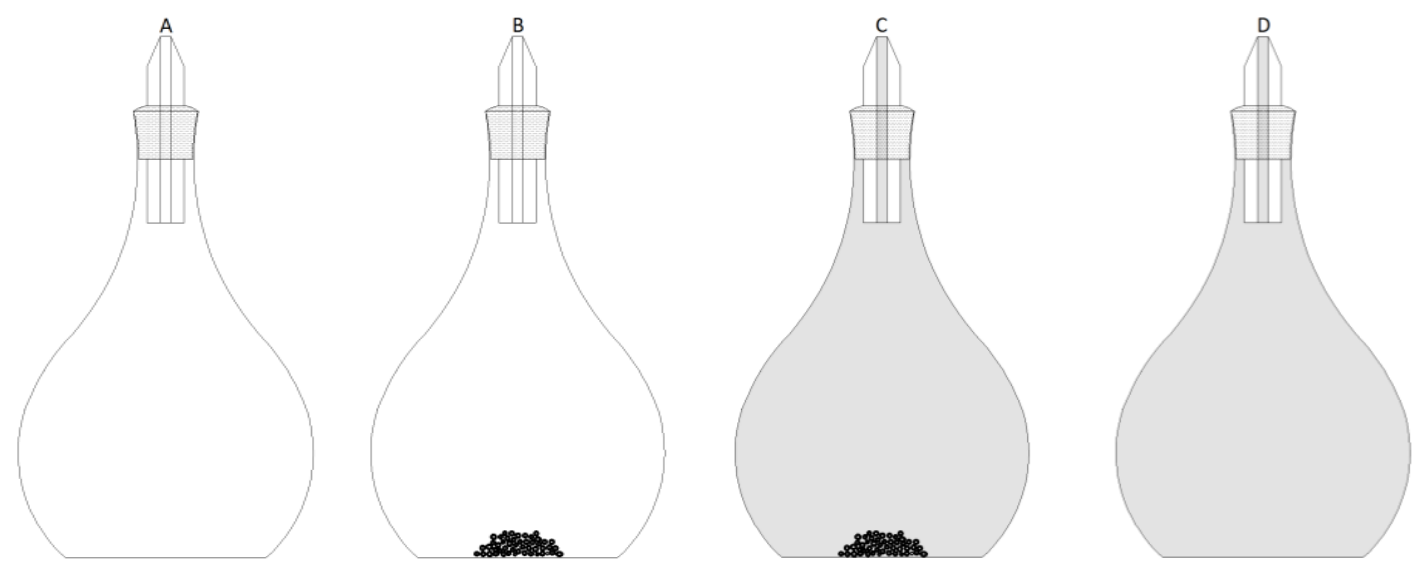

Figura A.1: Esquema sequencial para determinação de massa específica por picnometria.

Legenda: A - picnômetro vazio (com ar) e seco, massa: $m_{1}$; B - picnômetro com a amostra e ar, massa: $m_{2}$; $C$ picnômetro com a amostra e com líquido (água) e sem bolhas, massa: $m_{3}$; $D$ - picnômetro preenchido somente com líquido (água), massa: $\mathrm{m}_{4}$.

O volume efetivo do picnômetro é dado por:

$V_{\text {pic }}=\frac{\text { massa de água na condição } \mathrm{D}}{\rho_{\mathrm{H}_{2} \mathrm{O}}}=\frac{m_{4}-m_{1}}{\rho_{\mathrm{H}_{2} \mathrm{O}}}$

A massa da amostra (aqui adotada como sólida) é dada por:

$m_{s}=m_{2}-m_{1}$

Por seu turno, o volume ocupado pela amostra é o volume efetivo do picnômetro diminuído do volume ocupado pela água na condição C. Esse volume de água é dado por:

$V_{\mathrm{H}_{2} \mathrm{O}_{-} \mathrm{C}}=\frac{\text { massa de água na condição } \mathrm{C}}{\rho_{\mathrm{H}_{2} \mathrm{O}}}=\frac{m_{3}-m_{2}}{\rho_{\mathrm{H}_{2} \mathrm{O}}}$

Empregando-se as equações A.1 e A.2, o volume do sólido será dado por:

$V_{S}=V_{p i c}-V_{H_{2} O-C}=\frac{m_{4}-m_{1}}{\rho_{H_{2} \mathrm{O}}}-\frac{m_{3}-m_{2}}{\rho_{\mathrm{H}_{2} \mathrm{O}}}=\frac{\left(m_{4}+m_{2}\right)-\left(m_{1}+m_{3}\right)}{\rho_{\mathrm{H}_{2} \mathrm{O}}}$

Considerando que a massa específica é a razão entre a massa e o volume, a massa específica da amostra será dada, finalmente, dividindo-se a equação A.2 pela A.4:

$$
\rho_{s}=\frac{m_{2}-m_{1}}{\frac{\left(m_{4}+m_{2}\right)-\left(m_{1}+m_{3}\right)}{\rho_{\mathrm{H}_{2} \mathrm{O}}}}=\frac{\left(m_{2}-m_{1}\right) \times \rho_{\mathrm{H}_{2} \mathrm{O}}}{\left(m_{4}+m_{2}\right)-\left(m_{1}+m_{3}\right)}
$$

Nota: para medidas muito acuradas, o empuxo devido ao peso do ar deve ser considerado, como mostrado, por exemplo, em Smith (1996). 